\title{
Model sensitivity in the effect of Antarctic sea ice and stratification on atmospheric $\mathrm{pCO}_{2}$
}

\author{
David E. Archer, ${ }^{1}$ Pamela A. Martin, ${ }^{1}$ Jose Milovich, ${ }^{2}$ Victor Brovkin, ${ }^{3}$ \\ Gian-Kasper Plattner, ${ }^{4,5}$ and Carrie Ashendel ${ }^{1}$ \\ Received 24 January 2002; revised 5 June 2002; accepted 5 November 2002; published 11 March 2003.
}

[1] Several recent papers have demonstrated a decrease in atmospheric $\mathrm{pCO}_{2}$ resulting from barriers to communication between the deep sea and the atmosphere in the Southern Ocean. Stephens and Keeling [2000] decreased $\mathrm{pCO}_{2}$ by increasing Antarctic sea ice in a seven-box model of the world ocean, and Toggweiler [1999] showed a similar response to Southern Ocean stratification. In box models the $\mathrm{pCO}_{2}$ of the atmosphere is controlled by the region of the surface ocean that fills the deep sea [Archer et al., 2000a]. By severing the Southern Ocean link between the deep sea and the atmosphere, atmospheric $\mathrm{pCO}_{2}$ in these models is controlled elsewhere and typically declines, although the models range widely in their responses. "Continuum models," such as three-dimensional (3-D) and 2-D general circulation models, control $\mathrm{pCO}_{2}$ in a more distributed way and do not exhibit box model sensitivity to high-latitude sea ice or presumably stratification. There is still uncertainty about the high-latitude sensitivity of the real ocean. Until these model sensitivities can be resolved, glacial $\mathrm{pCO}_{2}$ hypotheses and interpretations based on Southern Ocean barrier mechanisms (see above mentioned references plus Elderfield and Rickaby [2000], Francois et al. [1998], Gildor and Tziperman [2001], Sigman and Boyle [2000], and Watson et al. [2000]) are walking on thin ice. INDEX TERMS: 4842 Oceanography: Biological and Chemical: Modeling; 4835 Oceanography: Biological and Chemical: Inorganic marine chemistry; 4805 Oceanography: Biological and Chemical: Biogeochemical cycles (1615); 4806 Oceanography: Biological and Chemical: Carbon cycling; 4572 Oceanography: Physical: Upper ocean processes; KEYWORDS: glacial pCO2, Southern Ocean, sea ice, stratification

Citation: Archer, D. E., P. A. Martin, J. Milovich, V. Brovkin, G.-K. Plattner, and C. Ashendel, Model sensitivity in the effect of Antarctic sea ice and stratification on atmospheric $\mathrm{pCO}_{2}$, Paleoceanography, 18(1), 1012, doi:10.1029/2002PA000760, 2003.

\section{Model Intercomparison}

[2] It is straightforward to test the sea ice hypothesis in any ocean carbon cycle model, and we have attempted to do so (Figure 1). We simply put a mask to prevent gas exchange poleward of $55^{\circ} \mathrm{S}$, in six different models ranging from simple box models to primitive equation GCMs. Consistent with the box model experiments, and for simplicity, we held circulation and biological uptake unaffected by the addition of the ice. CLIMBER-2 is an intermediate complexity coupled ocean atmosphere model [Petoukhov et al., 2000], the ocean component of which is a set of 2-D zonal mean circulation models which converge at the Southern Ocean [Stocker et al., 1992]. Bern is the current version of the Stocker et al. [Stocker et al., 1992] 2-D model. HAMOCC2 is an implicit offline tracer advection

\footnotetext{
${ }^{1}$ Department of Geophysical Sciences, University of Chicago, Chicago, Illinois, USA.

${ }^{2}$ Lawrence Livermore National Laboratory, Livermore, California, USA.

${ }^{3}$ Potsdam Institute for Climate Impact Research, Potsdam, Germany.

${ }^{4}$ Climate and Environmental Physics, Physics Institute, University of Bern, Bern, Switzerland.

${ }^{5}$ Now at Biogeochemistry Group, Institute of Geophysics and Planetary Physics, University of California, Los Angeles, California, USA.

Copyright 2003 by the American Geophysical Union. 0883-8305/03/2002PA000760\$12.00
}

scheme used for many geochemical studies [Maier-Reimer, 1993]. The version we use here is the water-only model from Archer et al. [2000b]. POP is a primitive equation model on a traditional C-grid, using Gent and McWilliams [1990] and KPP [Large et al., 1994] mixing parameterizations . The biological component of this model conforms to the OCMIP-2 [Orr, 1999] specifications. POP and the Bern model restore sea surface nutrients toward observed seasonal values, remineralize at depth, and take up and release dissolved carbon and alkalinity according to standard Redfield ratios. CLIMBER-2 and HAMOCC2 predict sea surface nutrients rather than restoring to observations, but the overall effect on carbon cycling is similar.

[3] The results (Figure 1) are clear; we only see significant $\mathrm{CO}_{2}$ draw down in the Stephens and Keeling [2000] and the Toggweiler [1999] box models. Other standard box models, the 3-box model and Pandora, show slight draw down but nothing as dramatic as these two (Figure 1a). All but one of the "continuum" models (3- and 2-D GCMs) show, if anything, a slight increase in $\mathrm{pCO}_{2}$ with increasing ice cover (Figure 1b).

\section{What Controls $\mathrm{pCO}_{2}$ in Box Models}

[4] Although the Southern Ocean barrier theory relies on the biological cycle in the ocean to work, we can understand the mechanism most easily by starting with abiotic model experiments. Figure 2, reprinted from 

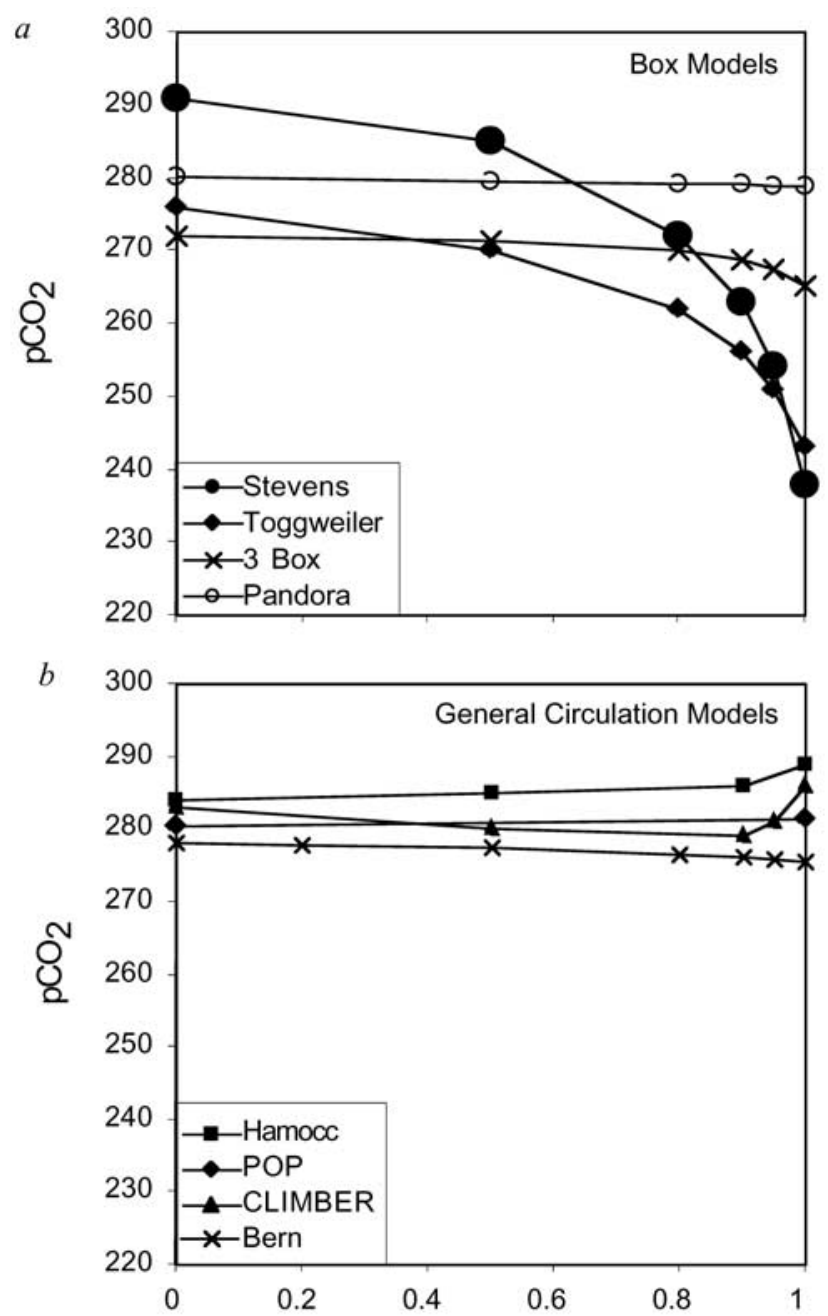

Fractional Southern Ocean Sea Ice Cover

Figure 1. Atmospheric $\mathrm{pCO}_{2}$ over global ocean carbon cycle models, plotted as a function of sea ice cover in the Southern Ocean (defined as poleward of $55^{\circ} \mathrm{S}$ in the gridded general circulation models). (a) Box models. (b) General circulation models.

Archer et al. [2000a], shows a super-simple box model of the ocean, with two identically sized surface boxes at warm and cold temperatures, and a deep box. The flow consists of an overturning circulation only. The model is initialized with an inventory of alkalinity and $\mathrm{CO}_{2}$ and run to equilibrium. The $\mathrm{pCO}_{2}$ of the atmosphere in equilibrium reflects which of the surface boxes exerts control of atmospheric $\mathrm{pCO}_{2}$ : if the cold surface box is in charge, then atmospheric $\mathrm{pCO}_{2}$ will be low because $\mathrm{CO}_{2}$ is more soluble in cold water. When the circulation is normal, i.e., downwelling from the cold box and upwelling to the warm, atmospheric $\mathrm{pCO}_{2}$ is low, reflecting atmospheric control by the cold surface box. When the circulation is reversed, the warm surface box controls $\mathrm{pCO}_{2}$, which rises to nearly twice the normal circulation value. The atmosphere equilibrates with the ocean at the temperature of the downwelling box.
[5] This behavior can be understood as follows. First, the deep box is large and its chemistry remains close to that of the ocean mean (more on this conceptual approximation below). Second, the steady state solution to the model has the chemistry of the downwelling box equal to the chemistry of the deep sea. It must be so, or else the chemistry of the deep sea would be changing, which is not the steady state. The downwelling box $\mathrm{CO}_{2}$ concentration is therefore required to be close to the ocean mean. On the other hand, the chemistry of the upwelling box is free to yield to atmospheric forcing. In the end, the atmosphere comes close to equilibrium with the mean chemistry of the ocean, at the temperature of the downwelling box. The crucial

$a$

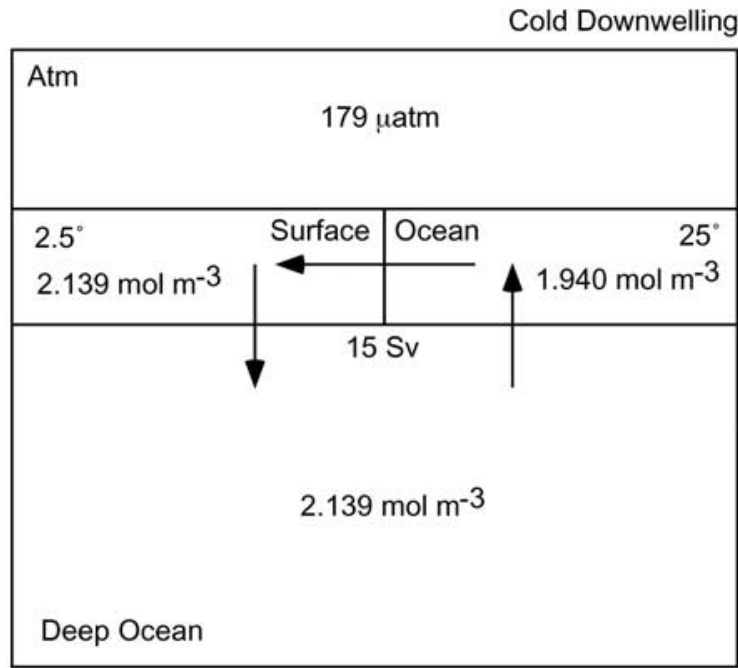

$b$

Warm Downwelling

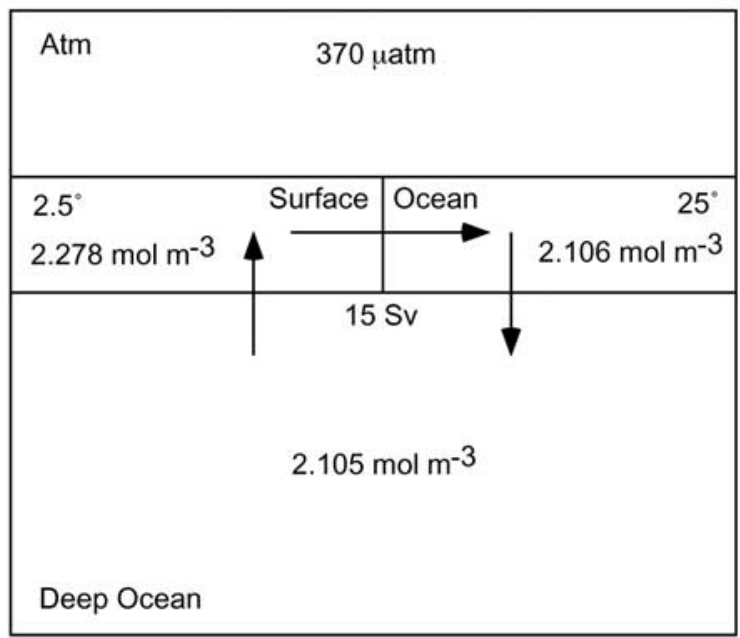

Figure 2. A simple abiotic ocean carbon cycle box model showing that the surface ocean box that fills the deep box also controls the $\mathrm{pCO}_{2}$ of the atmosphere. The plot shows temperatures, total $\mathrm{CO}_{2}$ concentrations, and fluxes in Sv. (a) With normal overturning circulation. (b) With reversed overturning circulation. 
$a$

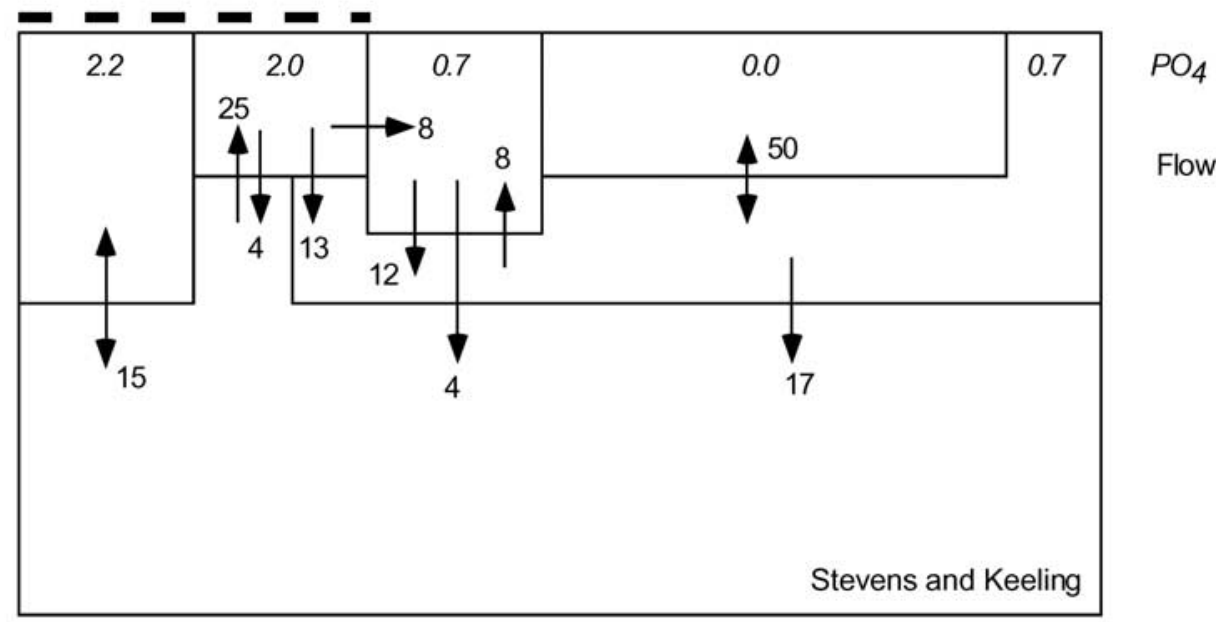

$b$

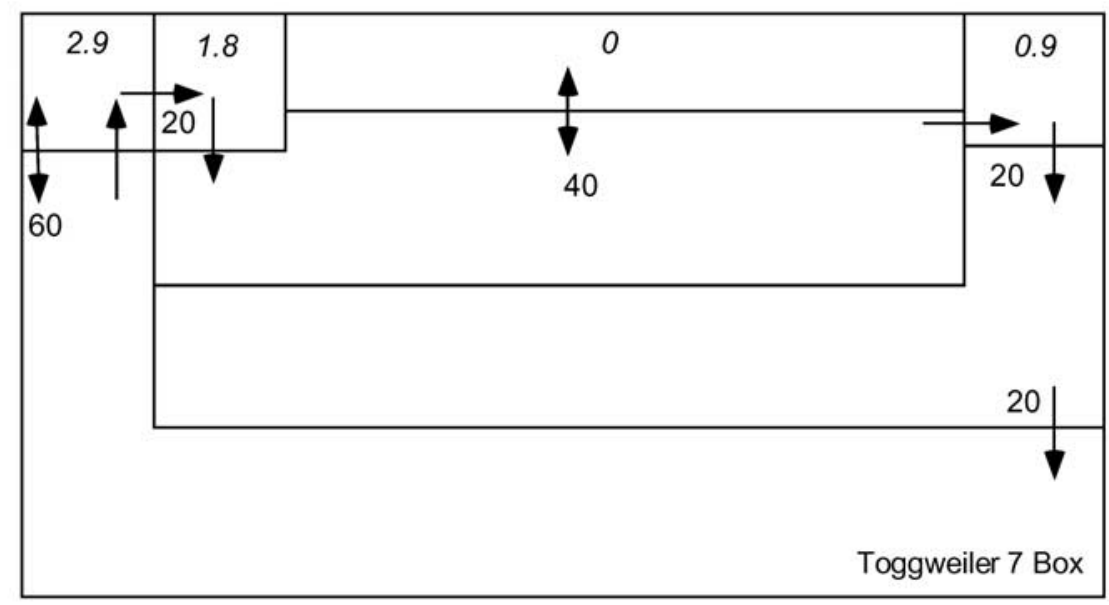

Figure 3. Schematic of box models from (a) Stephens and Keeling [2000] and (b) Toggweiler [1999]. Arrows represent water flows in Sverdrups, and italicized numbers show sea surface $\mathrm{PO}_{4}$ concentrations. South is to the left.

conclusion is that the downwelling surface box controls the $\mathrm{pCO}_{2}$ of the atmosphere. We will further demonstrate and test this conclusion below.

\section{Stephens and Keeling Sea Ice Model}

[6] The Stephens and Keeling box model (Figure 3a) is more complex than the simple three-box model in two regards. First, the deep ocean is filled from two sources, the Southern Ocean and the North Atlantic. Abiotic experiments (Figure 4) allow us to work out the implications of this. When the Southern Ocean surface is exposed to the atmosphere, the deep sea $\mathrm{CO}_{2}$ concentration is a weighted mean of the surface concentrations from the Southern Ocean and the North Atlantic (Figure 4a). Atmospheric $\mathrm{pCO}_{2}$ equilibrates with the deep sea $\mathrm{CO}_{2}$ concentration at a temperature between that of the two surface downwelling boxes. The colder box picks up $\mathrm{CO}_{2}$ from the atmosphere, and the warmer one loses a bit, relative to the deep-sea value.

[7] When sea ice is increased to $99 \%$ coverage (as found by Stephens and Keeling [2000]), the Southern Ocean surface box essentially becomes a subsurface extension of the deep ocean, and both $\mathrm{CO}_{2}$ concentrations converge to the concentration of the North Atlantic surface (Figure 4b). Covering the Southern Ocean forces the atmosphere to equilibrate with the deep sea at the temperature of the North Atlantic. The effect of sea ice on abiotic $\mathrm{CO}_{2}$ is small, because the only difference between Southern Ocean and North Atlantic is a temperature contrast of a few degrees.

[8] With the addition of nutrients and associated metabolic carbon, sea ice becomes more important, because nutrient concentrations are higher in the Southern Ocean 
$a$

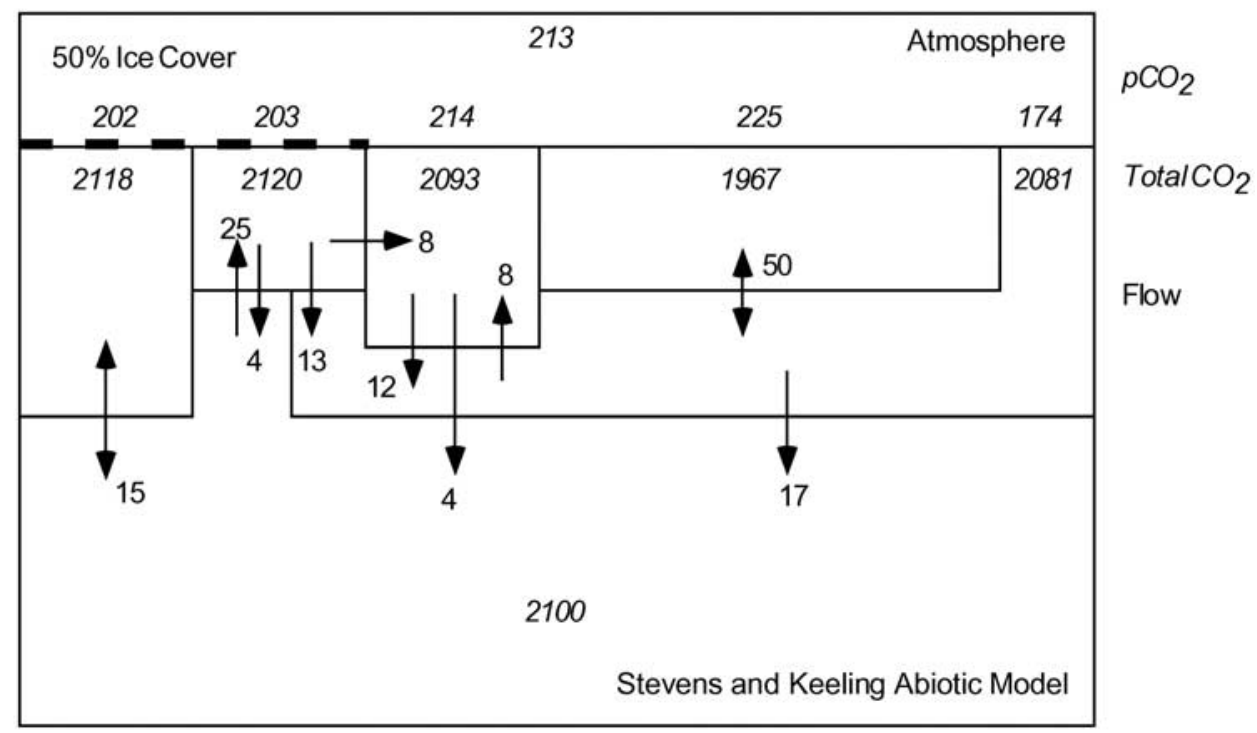

$b$

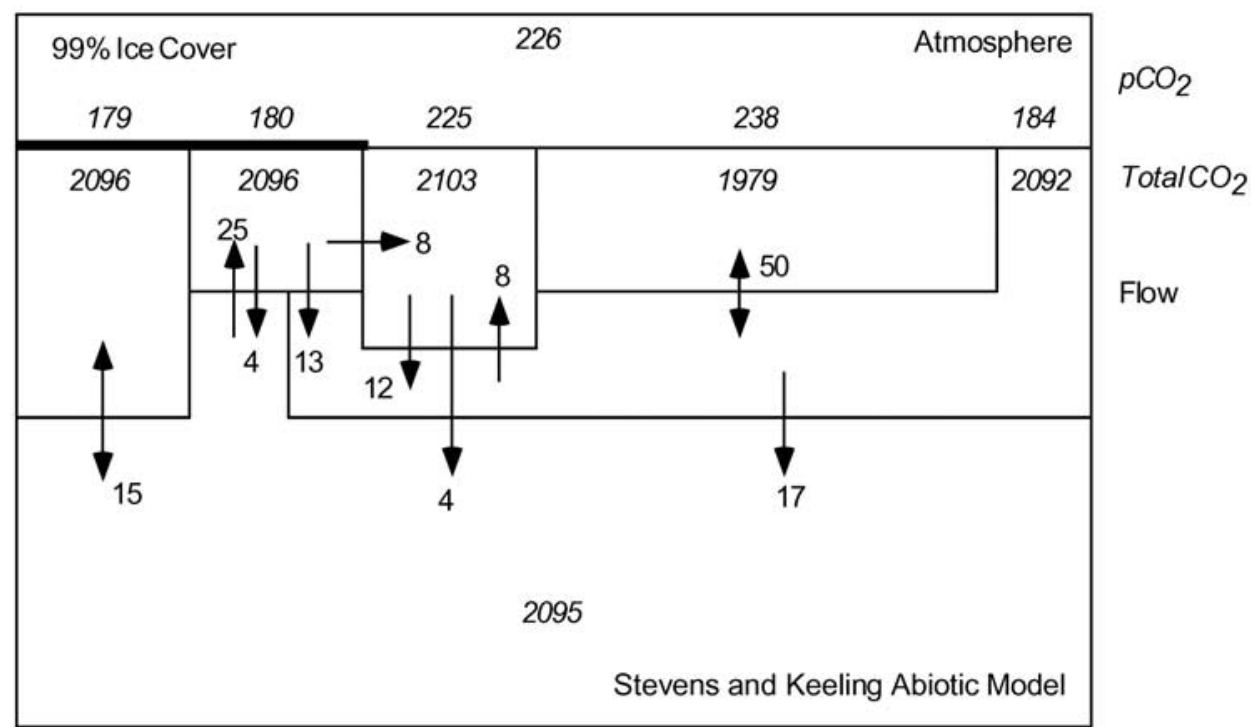

Figure 4. Abiotic carbon cycle results using the Stephens and Keeling [2000] box model. (a) When the Southern Ocean is exposed to the atmosphere, the atmosphere equilibrates with the chemistry of the deep sea at a temperature intermediate between that of the high South and North latitudes. (b) When the Southern Ocean is cut off from atmospheric contact, the atmosphere is controlled solely by the North Atlantic.

than in the North Atlantic. Complete ice cover shifts atmospheric $\mathrm{pCO}_{2}$ control from the high nutrient Southern Ocean to the lower nutrient North Atlantic, drawing down atmospheric $\mathrm{pCO}_{2}$. We can test this idea by lowering the nutrient concentration in the Southern Ocean and increasing its temperature to that of the North Atlantic, eliminating the contrast in $\mathrm{pCO}_{2}$ forcing. Atmospheric $\mathrm{pCO}_{2}$ drops to $201 \mathrm{ppm}$, but more to the point, changes in sea ice have no further effect on $\mathrm{pCO}_{2}$, because the contrast between Southern Ocean and North Atlantic has been eliminated. With no nutrient contrast between north and south, the sensitivity to sea ice disappears (Figure 5). This demonstrates that the sea ice mechanism for $\mathrm{CO}_{2}$ drawdown is seen to be a variant of a sea surface nutrient drawdown scenario.

\section{Stratification and the Toggweiler Model}

[9] The Toggweiler [1999] Southern Ocean stratification model operates similarly (Figure 3b). Here the barrier between the atmosphere and the deep sea is midwater column stratification, rather than sea ice. As found by 


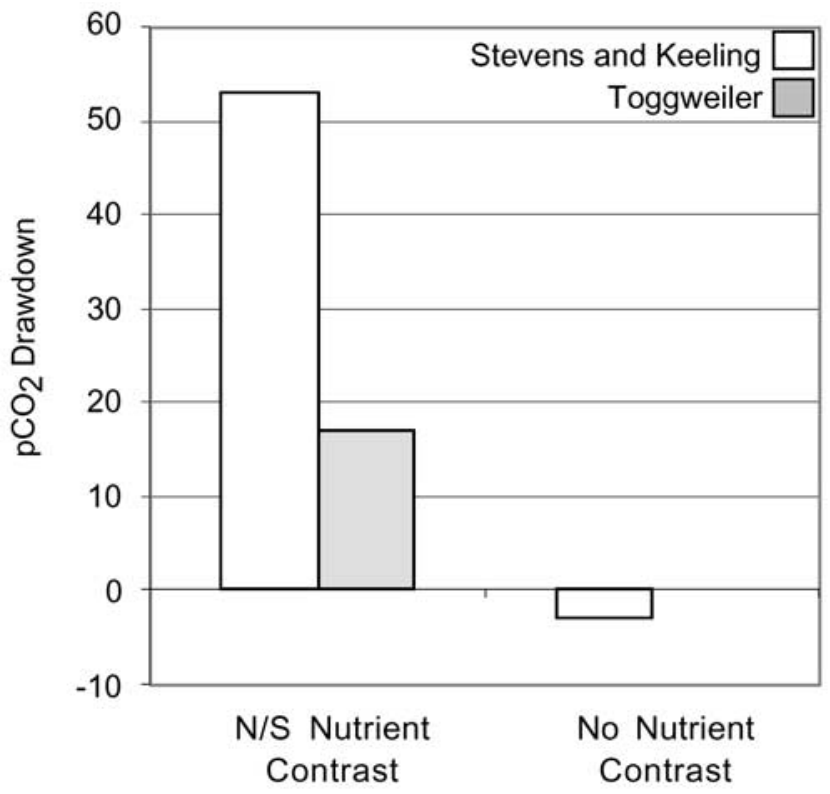

Figure 5. Effect of South/North high-latitude surface ocean nutrient contrast on the $\mathrm{pCO}_{2}$ sensitivity to Southern Ocean barriers (sea ice in the case of Stephens and Keeling, and stratification for Toggweiler). In both cases, when the nutrient concentrations are specified to be equal between North Atlantic and Southern Ocean, the models lose their sensitivity to their respective Southern Ocean barriers.

Stephens and Keeling, the model relies on a competition for the link between the atmosphere and the deep sea. Increasing the stratification between the Southern Ocean surface and the deep sea shifts control of the atmosphere to the North Atlantic. As with the Stephens and Keeling model, when nutrient and temperature contrasts between the North Atlantic and the Southern Ocean are eliminated, the $\mathrm{pCO}_{2}$ sensitivity to stratification disappears (Figure 5). This shows that the stratification hypothesis is also based on a nutrient drawdown mechanism.

\section{Box Model Intercomparison}

[10] The four box models tested (3 box, Pandora, Stevens and Keeling, and Toggweiler 7 box) responded quite differently to the imposition of sea ice in the Southern Ocean. We can use these differences to demonstrate and test the downwelling-box-controls-the-atmosphere theory described above. According to this theory, the surface ocean box that fills the deep sea will control the $\mathrm{pCO}_{2}$ of the atmosphere. If more than one box fills the deep sea, then the chemistry of the deep sea will be a weighted average of sources from the downwelling boxes. By analogy we expect the atmosphere to be controlled by the downwelling surface boxes weighted by the total downwelling fraction coming from each box.

[11] The oceanographic $\mathrm{pCO}_{2}$ forcing from each surface ocean box can be computed by running the model to equilibrium in the absence of gas exchange. These no-gasexchange end-members are determined by a combination of the soft and hard-tissue biological pumps and by temper- ature, and are shown for each model in Figure 6. The downwelling-weighted average $\mathrm{pCO}_{2}$ values, with and without the Southern Ocean, are also shown in Figure 6. In all cases isolating the Southern Ocean from the atmosphere decreases the $\mathrm{pCO}_{2}$ of the atmosphere, but the mechanism of drawdown differs between the models. In the 3 box model in particular, the imposition of Southern Ocean ice shifts the control of atmospheric $\mathrm{pCO}_{2}$ to the tropical surface ocean rather than a cold North Atlantic. Low nutrients in the tropics pull $\mathrm{pCO}_{2}$ down lower than in high latitudes in this model. The mechanisms and extent of $\mathrm{CO}_{2}$ drawdown with sea ice are idiosyncratic among the various box models.

[12] With one exception, the downwelling-weighted average $\mathrm{pCO}_{2}$ effect of sea ice in each model correlates well with the response of the full box models (Figure 1a), with the highest sensitivity from the Stevens and Keeling model, and the lowest for the 3 box model (Figure 7). The exception is the Toggweiler 7 box model, which differs from the others in that the deep box of this model does not dominate the volume of the ocean, as we had assumed in section 2. When most of volumes of the Thermocline and the North Atlantic boxes are donated to the deep box, the modified Toggweiler model conforms to the correlation exhibited by the rest of the models (Symbol "Tm" in Figure 7). The Toggweiler model was developed to explore the implications of a deep chemical divide in the ocean [Toggweiler, 1999], and we see here one interesting implication of this structure.

[13] We note also that the downwelling-weighted average $\mathrm{pCO}_{2} \mathrm{~s}$ are more sensitive to sea ice than the full box model $\mathrm{pCO}_{2} \mathrm{~s}$. This sensitivity arises from the implicit assumption in the downwelling-weighted calculation that the sizes of the atmospheric and the warm upper ocean carbon reservoirs are negligible relative to the larger deep sea. A no-gasexchange end-member $\mathrm{pCO}_{2}$ would impose itself quantitatively upon an infinitesimal atmosphere/surface ocean, but in the real models an increase in atmospheric $\mathrm{pCO}_{2}$ results in a decrease in the $\mathrm{pCO}_{2}$ of the deep sea. The atmosphere and the deep sea ultimately compromise. The magnitude of this effect can be estimated from the relative sizes of the deep sea and atmosphere/tropical surface ocean reservoirs. $\mathrm{CO}_{2}$ addition experiments show an eventual ocean $\mathrm{CO}_{2}$ uptake of $\sim 75 \%$ in the absence of $\mathrm{CaCO}_{3}$ compensation; i.e., a partitioning of 1:3 between the atmosphere and ocean [Archer et al., 1997]. If the warm tropical upper ocean is bundled with the atmospheric reservoir, then the partitioning between the deep sea and the atmosphere/surface ocean becomes more balanced, say $1: 2$ or $1: 1$. Disequilibrium between the atmosphere and the downwelling outcrop may also contribute to a decrease in atmospheric $\mathrm{pCO}_{2}$ sensitivity (J. Toggweiler et al., manuscript in preparation, 2003). We can allow for these effects by decreasing by some factor the deviation of $\mathrm{pCO}_{2}$ from the initial value of $270 \mu \mathrm{atm}$; a factor of about $40 \%$ brings the simplistic forcing predictions into line with the box model results (Figure 7).

[14] Atmospheric $\mathrm{pCO}_{2}$ control by the ocean is a complex, nonlinear topic, and different researchers seem to conceptualize its behavior in different ways. Here we have demonstrated that the downwelling-box-controls-the-atmosphere 
$a$

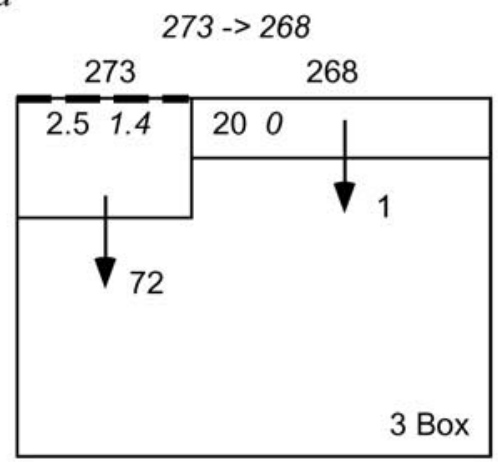

$c$

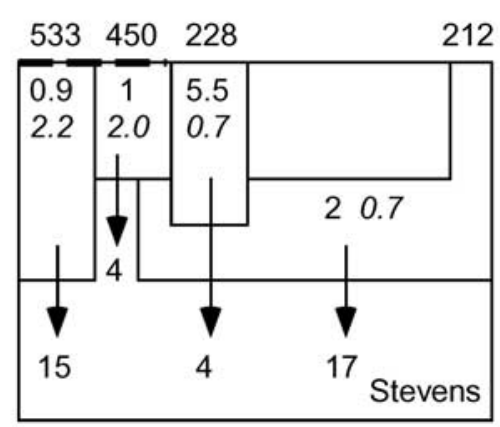

$b$

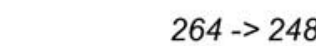

267300

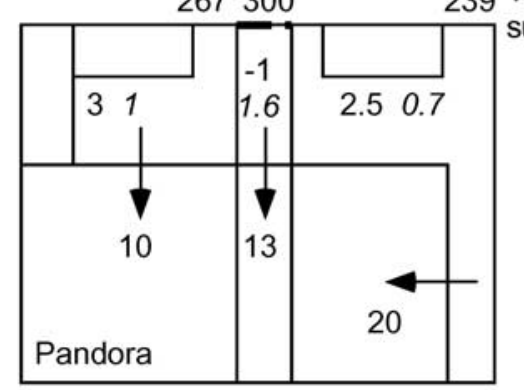

noice -> ice

No Gasex

surf. $\mathrm{pCO}_{2}$

$\mathrm{T} \mathrm{PO}_{4}$

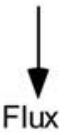

$d$

$356->199$

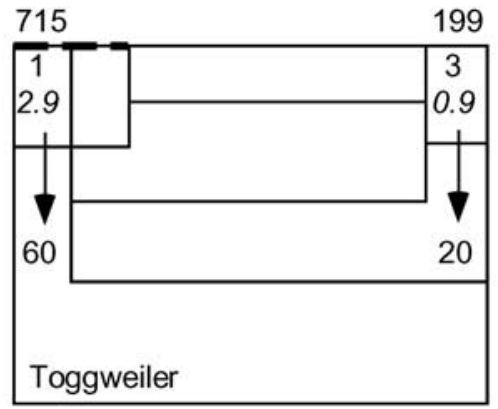

Figure 6. Sea surface temperature, phosphate, no-gas-exchange $\mathrm{pCO}_{2}$, and downwelling velocity of the downwelling surface boxes of four box models. Above each model, an atmospheric $\mathrm{pCO}_{2}$ is predicted by averaging the no-gas-exchange $\mathrm{pCO}_{2} \mathrm{~S}$ of the surface boxes, weighted by their downward velocities. When the Southern Ocean is eliminated from the averaging, the predicted $\mathrm{pCO}_{2}$ of the atmosphere drops in all cases; the effect is largest for the Stevens and Toggweiler models and smallest for the 3 box model.

theory is able to predict very simply the widely disparate effects of sea ice over a range of ocean box models.

\section{Why a Southern Ocean Barrier Does Not Work in GCMs}

[15] Broecker et al. [1999] and Archer et al. [2000a] showed that control of the atmospheric $\mathrm{pCO}_{2}$ is more diffuse with GCMs than in box models. Broecker's Harvardton Bear Equilibration Index (HBEI) is an indicator of the intensity of low-latitude control of $\mathrm{pCO}_{2}$, and can be

Figure 7. (opposite) Downwelling-weighted average $\mathrm{pCO}_{2} \mathrm{~S}$ compared with real steady state box model response to eliminating gas exchange in the Southern Ocean. $\mathrm{P}=$ Pandora, $3=3$ box, $\mathrm{S}=$ Stevens and Keeling, $\mathrm{T}=$ Toggweiler 7 box. $\mathrm{Tm}=$ a modified Toggweiler 7 box model, in which the volume of the volume of the Atlantic and Thermocline boxes (VA and VM from Toggweiler [1999]) are decreased to $0.3 \cdot 10^{16} \mathrm{~m}^{3}$ and $0.7 \cdot 10^{16} \mathrm{~m}^{3}$, respectively. Downwelling-weighted average $\mathrm{pCO}_{2} \mathrm{~S}$ correlate with the real impact of sea ice. Steady state model results are less sensitive to Southern Ocean gas exchange than predicted by the downwelling-weighted average $\mathrm{pCO}_{2} \mathrm{~s}$; this is a consequence of the nonnegligible size of the atmospheric and warm surface ocean carbon reservoirs (see text). used to calculate the fraction of high-latitude control. If one square meter of sea surface in the tropics had the same influence over atmospheric $\mathrm{pCO}_{2}$ as an average square meter of the sea surface (including high latitudes), then the HBEI index of that model would be 1 . In the 3-box model, the low latitudes cover $85 \%$ of the ocean surface, but

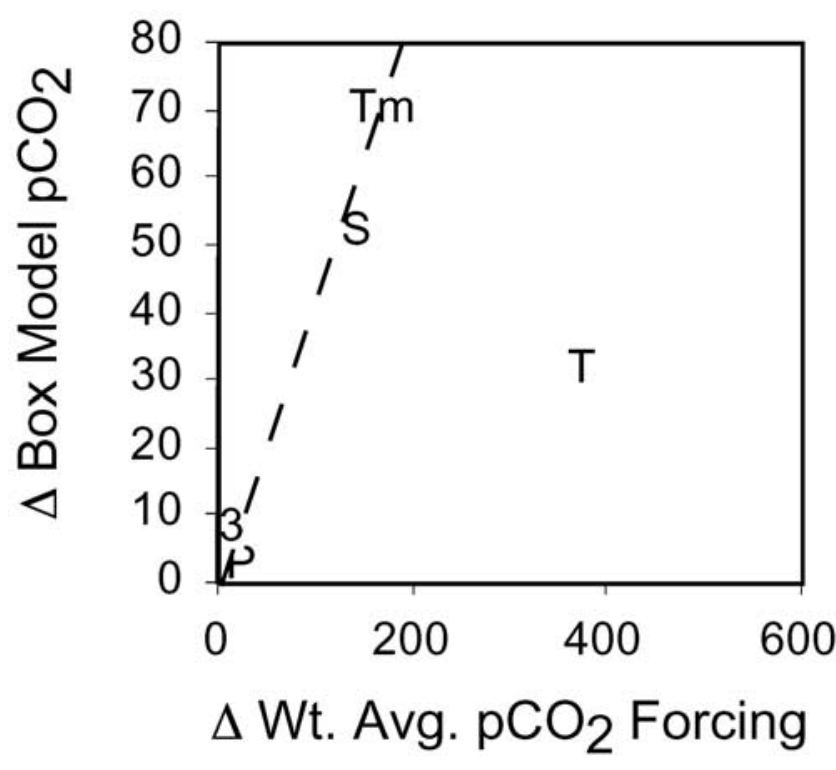


their influence is lower than would naively be expected, by a factor of the HBEI, which for this model is 0.11 . The low latitudes therefore exert $0.85 * 0.11=9 \%$ control, leaving the balance $(91 \%)$ to the high latitudes. Estimates for GCM behavior generally place the control more evenly between high and low latitudes. The HBEI index of GCMs is typically three times higher than in the 3-box model, breaking the high-latitude monopoly on determining the $\mathrm{pCO}_{2}$ of the atmosphere. In this type of model, the effects of a barrier in the Southern Ocean become considerably less important, because the Southern Ocean itself is less important to determining atmospheric $\mathrm{pCO}_{2}$.

\section{GCMs, Box Models, and the Real Ocean}

[16] The reason for the discrepancy between box models and GCMs is still far from clear. Archer et al. [2000a] invoked vertical diffusivity as one factor, although diffusion is insufficient to make a box model reproduce GCM behavior, and lack of diffusion is insufficient to make an isopycnal ocean circulation model, MICOM, reproduce the behavior of a box model. J. Toggweiler et al. (submitted manuscript, 2002) points to a smaller area of convection in GCMs than in box models to explain the discrepancy, which limits the equilibration between high-latitude surface ocean and the atmosphere. We will not resolve the issue here, but simply note that the high-latitude sensitivity of the real ocean is even more elusive than the reason for the difference between the different model types. It could turn out, in the end, that box models were right all along. However, until we know for sure, we advise skepticism in the sea ice and stratification Southern Ocean barrier theories applied to questions of glacial/interglacial $\mathrm{pCO}_{2}$ cycles.

\section{References}

Archer, D., H. Kheshgi, and E. Maier-Riemer, Multiple timescales for neutralization of fossil fuel CO2, Geophys. Res. Lett., 24, 405-408, 1997.

Archer, D., G. Eshel, A. Winguth, W. S. Broecker, R. T. Pierrehumbert, M. Tobis, and R. Jacob, Atmospheric pCO2 sensitivity to the biological pump in the ocean, Global Biogeochem. Cycles, 14, 1219-1230, 2000a.

Archer, D. E., A. Winguth, D. Lea, and N. Mahowald, What caused the glacial/interglacial atmospheric pCO2 cycles?, Rev. Geophys., 38, 159-189, 2000b

Broecker, W., J. Lynch-Steiglitz, D. Archer, M. Hofmann, E. Maier-Reimer, O. Marchal, T. Stocker, and N. Gruber, How strong is the Harvardton-Bear constraint?, Global Biogeochem. Cycles, 13, 817-821, 1999.

Elderfield, H., and R. E. M. Rickaby, Oceanic $\mathrm{C} / \mathrm{P}$ ratio and nutrient utilization in the glacial Southern Ocean, Nature, 405, 305-310, 2000.

Francois, R., M. A. Altabet, E.-F. Yu, D. M. Sigman, M. P. Bacon, M. Frank, G. Bohrmann, G. Bareille, and L. D. Labeyrie, Contribution of Southern Ocean surface-water stratification to low atmospheric $\mathrm{CO} 2$ concentration during the last glacial period, Nature, 389, 929-936, 1998.

Gent, P., and J. C. McWilliams, Isopycnal mixing in ocean circulation models, J. Phys. Oceanogr., 20, 463-474, 1990.
Gildor, H., and E. Tziperman, Physical mechanisms behind biogoechemical glacial-interglacial CO2 variations, Geophys. Res. Lett., 28, 2421-2424, 2001 .

Large, W. G., and S. C. Doney, Oceanic vertica mixing: A review and a model with nonloca boundary layer parameterization, Rev. Geophys., 32, 363-403, 1994.

Maier-Reimer, E., Geochemical cycles in an ocean general circulation model: Preindustrial tracer distributions, Global Biogeochem. Cycles, 7, 645-678, 1993.

Orr, J. C., On carbon-cycle model comparison, Tellus, 51, 509-510, 1999.

Petoukhov, V., A. Ganapolski, V. Brovkin, M. Claussen, A. Eliseev, C. Kubatzki, and S Rahmstorf, CLIMBER-2: A climate system model of intermediate complexity, I, Model description and performance for present climate, Clim. Dyn., 16, 1-17, 2000.

Sigman, D. M., and E. A. Boyle, Glacial/interglacial variations in atmospheric carbon dioxide, Nature, 407, 859-869, 2000.

Stephens, B. B., and R. F. Keeling, The influence of Antarctic sea ice on glacial-interglacial CO2 variations, Nature, 404, 171-174, 2000.

Stocker, T. F., D. G. Wright, and L. A. Mysak, A zonally averaged, coupled ocean-atmosphere model for paleoclimatic studies, J. Clim., 5, $773-797,1992$.
Toggweiler, J. R., Variation of atmospheric CO2 by ventilation of the ocean's deepest water, Paleoceanography, 14, 571, 1999.

Watson, A. J., D. C. E. Bakker, A. J. Ridgewell, P. W. Boyd, and C. S. Law, Effect of iron supply on Southern Ocean CO2 uptake and implications for glacial atmospheric CO2, Nature, 407, 730-733, 2000

D. E. Archer, C. Ashendel, and P. A. Martin, Department of Geophysical Sciences, University of Chicago, 5734 South Ellis Ave., Chicago, IL 69637, USA. (archer@starbuck.uchicago.edu; cmashend@starbuck.uchicago.edu)

V. Brovkin, Climate System Department, Potsdam Institute for Climate Impact Research, P.O. Box 601203, D-14412 Potsdam, Germany. (victor@pik-potsdam.de)

J. Milovich, Center for Applied Scientific Computing, Lawrence Livermore National Laboratory, P.O. Box 808, L-56, Livermore, CA 94551, USA. (milovich1@1lnl.gov)

G.-K. Plattner, Biogeochemistry Group, Institute of Geophysics and Planetary Physics, 5853 Slichter Hall, University of California, Los Angeles, CA 90095-1567, USA. ( plattner@igpp. ucla.ch) 